\title{
O SERTÃO COMO PAISAGEM: A RELAÇÃO SUBJETIVA DO ESPAÇO EM GALILEIA, DE RONALDO CORREIA DE BRITO
}

\section{THE BRAZILIAN BACKLANDS AS LANDSCAPE: THE SPACE SUBJECTIVE RELATION IN RONALDO CORREIA DE BRITO'S GALILEIA}

\author{
Ana Carolina Negrão Berlini de Andrade \\ Universidade Regional do Cariri, Missão Velha, Ceará, Brasil \\ nba.anacarolina@gmail.com
}

Resumo: Este artigo pretende analisar as relações entre subjetividade e espaço no romance Galileia (2009), de Ronaldo Correia de Brito. Nessa obra, percebemos que a descrição do sertão, espaço onde transcorre a narrativa, é mediada pela psicologia do narrador-protagonista, cujos estados emocionais direcionam a apreensão e a criação de uma Paisagem literária, segundo terminologia de Michael Jakob. Assim, o nosso objetivo é demonstrar como são construídas as imagens espaciais, utilizando, para tanto, as concepções de Jakob, para quem a Paisagem literária é marcada pelas relações de subjetividade e de distanciamento do sujeito em relação à natureza. A fim de explicitar a construção da espacialidade em Galileia, também utilizaremos o conceito de cronotopo, de Bahktin (1988), e de memória-acontecimento, de Mariana Luz Pessoa de Barros (2011).

Pallavras-chave: Ronaldo Correia de Brito; Galileia; Sertão; Paisagem literária; Michael Jakob

Abstract: This paper intends to analyze the relations between subjectivity and space in Ronaldo Correia de Brito's novel Galileia (2009). In Brito'work the description of the Brazilian backlands, space where the narrative happens, is mediated by the narrator-protagonist psychology, in which emotional states direct the creation and apprehension of a Literary landscape, according to Michael Jakob's terminology. Therefore, the objective here is to show how the spatial images are built using, to this end, Jakob's concepts, to whom the Literary Landscape is marked by relations of the subject's subjectivity and detachment towards nature. To explicit Galileia's spatial build the paper also uses Bakhtin's (1988) chronotrope concept, as well as Mariana Luz Pessoa de Barros's (2011) event memory concept.

Keywords: Ronaldo Correia de Brito; Galileia; Brazilian backlands; Literary landscape; Michael Jakob 
Galileia (2008), romance de estréia de Ronaldo Correia de Brito e ganhador do prêmio São Paulo de Literatura, narra a viagem de Adonias, narrador-protagonista, ao sertão do Inhamuns para um evento familiar. No entanto, apesar de narrar fatos envolvendo a família de maneira geral, os eventos dessa narrativa estão colocados em razão de sua relação com Adonias, seu psicologismo e seu ponto de vista, determinante na descrição do espaço que o circunda. Por essa razão, acreditamos que o espaço em Galileia enquadra-se na categoria de Paisagem nas definições de Jakob $(2005,2009)$, para quem esta é uma construção imagética resultante de uma relação intencional com a natureza por parte de um sujeito subjetivo.

Segundo o autor, a Paisagem como experiência "pessoal" é muito posterior ao gênero pictórico homônimo, o qual a influencia determinantemente: "Inicialmente, a paisagem é quadro/pintura, representação artística, e somente muito mais tarde, sobretudo devido à práxis artística, transforma-se em outra coisa: a experiência de um pedaço de espaço percebido de uma vez por alguém" (JAKOB, 2009, p. 29, tradução nossa) ${ }^{1}$.

A "experiência paisagística", no entanto, só é possível a partir do momento em que o homem deixa de estar em conjunção com a natureza, não mantendo com esta uma relação "orgânica". Por essa razão, aqueles que possuem uma relação "pré-reflexiva" e mítica com a natureza (JAKOB, 2009, p. 40), tais como o camponês, o caçador, o pastor, etc., não são capazes de apreender uma Paisagem na natureza que os circunda. Para que esta exista, é necessário um grau de separação entre o homem e o espaço natural, de modo que quem "inventa" a Paisagem é o citadino, que percebe uma ruptura irrevogável entre si próprio e a natureza, agora considerada um "outro" (JAKOB, 2009, p. 40).

O sujeito representa o primeiro elemento indispensável ao surgimento da paisagem. Entendemos por sujeito uma pessoa dotada de subjetividade, isto é, um ser humano que se distingue por meio do seu ser-no-mundo particular. Um outro modo de caracterizá-lo, sem no entanto facilitar a classificação do sujeito em questão, consiste em identificá-lo enquanto ser 'moderno'. Tanto a subjetividade quanto a modernidade remetem mais a um período histórico que a uma atitude ou uma disposição./ Ser sujeito da modernidade indica uma separação ou uma ruptura com o passado [...], o sentimento e a consciência da perda de um estado anterior e o debutar de uma nova era, a moderna. Subjetividade e modernidade implicam a superação de um limiar, o advento de uma crise fundadora (JAKOB, 2009, p. 31, tradução nossa) $)^{2}$.

Logo, é essencial que o sujeito se reconheça como tal e perceba a diferença fundamental que o separa da natureza, tendo os conceitos de individualidade e subjetividade bem delimitados, processo cuja evolução culmina na era moderna. Jakob chega a afirmar que a experiência paisagística, além de paradigma da modernidade, é importante para compreensão e explicação da subjetividade em si como valor culturalmente construído (JAKOB, 2009, p. 33).

\footnotetext{
1 "Il paesaggio non è inizialmente che quadro, rappresentazione artistica, e soltando molto più tardi, sopratutto alla prassi artistica, diventerà altra cosa: l'esperienza di un pezzo di spazio percepito in una sola volta da qualcuno (JAKOB, 2009, p. 29).

2 Il soggetto rappresenta il primo elemento indispensabile alla comparsa del paesaggio. Intendiamo per soggetto una persona dotata di soggetività, cioè un essere umano che si distingue attraverso il suo essere-nel-mondo particolare. Un altro modo di carrratterizzarlo, senza peraltro facilitare la determinazione del soggetto in questione, consiste nell'identificarlo in quanto essere 'moderno'. La soggetività e la modernità rinviano entrambe più a un periodo storico che a un'attitudine o a una disposizione./Essere soggetto della modernità indica una separazione o rottura com il passato [...], il sentimento e la coscienza della perdita di uno stato anteriore e del debutto di una nuova era, per l'appuntamento moderna. Soggetività e modernità implicano il superamento di una soglia, 1'avvento di una crise fondatrice (JAKOB, 2009, p. 31).
} 
No caso específico da literatura, abordada em Paisagem e literatura (2005), Jakob estabelece perguntas que visam nortear a delimitação do conceito: a Paisagem se refere a uma moldura narrativa, a uma ambientação literária ou a uma imagem poética? Na constituição da Paisagem devemos levar em conta a retórica convencional ou as reflexões de um sujeito poético? (JAKOB, 2005, p. 9).

Respondendo a esses questionamentos, Jakob estabelece uma diferença fundamental entre paisagem na literatura e Paisagem literária, diferença esta ancorada na acepção de um sujeito subjetivo/moderno. $\mathrm{O}$ autor estabelece algumas características constantes à Paisagem literária: referência espacial à natureza, que é abordada a partir da perspectiva de um sujeito consciente de sua individualidade e da "outridade" da natureza, em um momento histórico e contextual pós advento das ciências naturais, quando a abordagem da natureza não é mais alegórica, mítica, mas deve ser interpretada pelo sujeito racional (JAKOB, 2009). Dentreessas características, o autor dá especial atenção à construção da subjetividade:

Logo, o texto que definiremos como paisagem literária deverá se referir à experiência (estética) da natureza por parte de um sujeito, a uma consciência, e, de acordo com o próprio gênero literário, surgirá respectivamente a perspectiva do sujeito poético, heroico ou autobiográfico. A paisagem literária não é, certamente, uma simples restituição/recuperação mimética da real experiência estética de um sujeito transferida para a literatura. Consequentemente, as representações literárias da paisagem não se referem, a não ser indiretamente, ao autor ou à realidade, mas devem ser consideradas como funcionais ao texto. Se existem linhas demarcatórias a serem traçadas, então a distinção fundamental não é entre a descrição pictórica e a representação literária da ação, mas sim entre a descrição literária da natureza de um lado e, de outro, a paisagem literária [...] Essas descrições tendem a ter caráter ornamental, e nunca transcendem realmente a dimensão linguística, porque se limitam a reproduzir infinitos topoi literários, gerando sequências de imagens irreais, privadas de referentes. Diversamente das paisagens literárias, as descrições reúnem apenas inventários da natureza, isto é, aquilo que é reproduzido é sempre uma imagem essencialista e irreal da natureza, as "belas naturezas", como natureza útil e domesticada. Por conta da falta de uma representação em perspectiva, essas não oferecem quase nada para "ver", permanecendo no elemento puramente linguístico, ou mesmo mostrandoalgo só do ponto de vista ideal e inanimado. A natureza ideal bucólica (locus amoenus), apesar de já se aproximar da paisagem literária, pertence, antes, à categoria da descrição [...]. Somente nos textos que remetem à subjetividade, somente onde esta está bem ancorada no texto, surgem imagens inovadoras e expressivas da natureza, ou seja, paisagens literárias./ Portanto, podemos falar de paisagens literárias quando, direta ou indiretamente, a experiência vivida da natureza é conotada por parte de um observador. (JAKOB, 2005, p. 40, tradução nossa, grifo nosso) $)^{3}$.

\footnotetext{
${ }^{3}$ Il testo che definiremo quindi come paesaggio letterario dovrà riferisi all’esperienza (estetica) della natura da parte di un soggetto, ad una coscienza, e, a seconda del genere letterario stesso, emergerà rispettivamente la prospettiva del soggetto poetico, eroico o autobiograficoi. Il paesaggio letterario non è, beninteso, la restituizione mimetica della reale esperienza estetica di un soggetto semplicemente traslata nella letteratura. Di conseguenza le rappresentazioni letterarie del paesaggio non vanno riferite, se non indirettamente, all'autore o alla realtà, ma sono da considerare come funzionali al testo. Se vi sono linee di demarcazione da tracciare, allora la distinzione fondamentale non è tra descrizione pittorica e rappresentazione letteraria dell’azione, bensì tra descrizione letteraria della natura da una parte e paesaggio letterario dall'́altra.[...]Queste descrizioni tendono ad avere carattere ornamentale, e non trascendono mai realmente la dimensione linguistica, poiché si limitano a riprodurre infiniti topoi letterari, generando sequenze di immagini irreali e prive di referente. Diversamente dai paesaggi letterari, le descrizioni letterarie compilano solo inventari della natura; ciò che in esse viene riprodotto è sempre un'immagine essenzialistica ed irreale della natura, la 'belle nature' in quanto natura utile ed addomesticata. A causa della
} 
Desse modo, a experiência subjetiva do espaço não se caracteriza apenas pelo encontro com a natureza, mas pelo estabelecimento de uma relação "pessoal" com esta, alcançada por meio de uma perspectiva subjetiva, que pode ser tanto do eu-lírico, quanto do narrador, do protagonista, dos personagens ou, ainda, variável (JAKOB, 2005, p. 44). O importante, segundo Jakob, é que exista a "perspectiva de uma consciência" (JAKOB, 2005), isto é, um recorte do espaço baseado na experiência subjetiva de um sujeito. Essa assegura a unidade imagética do espaço, portanto, da Paisagem, e estabelece, a partir desse ponto de vista central, um ponto de fuga para o texto inteiro (JAKOB, 2005, p. 41).

A perspectiva de um sujeito garante uma maior expressividade à abordagem do espaço, pois conota as impressões de um ser, ainda que fictício, a partir do qual se constrói um universo de valores e se (re)cria uma experiência "empírica", recorrendo à estesia. Desse modo, a estética dessas imagens-paisagísticas é contextual, porque é somente a partir de seus universos diegéticos que ela adquire e propõe significados, diferenciando-se das descrições que, supostamente, são apenas retóricas.

Além disso, percebe-se que Jakob associa, ainda que não diretamente, a Paisagem à Imagem poética. No entanto, segundo a nossa leitura, a Imagem poética é mais ampla e geral que a Paisagem, que seria uma especificação da primeira, conquanto se refere apenas à experiência estética do espaço natural.

Por fim, a perspectiva também estabelece um recorte, um enquadramento específico do espaço que "oferece um pedaço de natureza que remete, além das bordas visíveis, à totalidade invisível. O mecanismo do enquadramento obriga o olhar receptor a ocupar o lugar a partir do qual criará uma representação mental da representação pictórica" (JAKOB, 2009, p. 43-44, tradução nossa). Desta feita, o leitor é parte integrante na constituição da representação da Paisagem.

No caso da obra em questão, percebemos que a falta de uma descrição exaustiva da natureza sertaneja em Galileia se dá sob o paradigma da construção de uma Paisagem, isto é, de uma Imagem poética espacial, baseada na subjetividade de Adonias, cuja perspectiva psicológica rege todo o romance, incluindo a perspectiva visual/espacial. Assim, de um lado temos um recorte do espaço, executado pelo olhar subjetivo de Adonias, e, do outro temos um repertório imagístico sobre o sertão, o qual influencia diretamente na construção da representação espacial pelo leitor.

Nesse artigo, procuraremos, portanto, desvelar os significados instaurados a partir do narrador-protagonista pela/na Paisagem, a qual, nunca é original, mas intertextual - o que influencia inclusive a experiência paisagística in situ (JAKOB, 2009).

A obra começa com a descrição da viagem de Adonias, no momento em que o narrador-protagonista do romance adentra o sertão propriamente dito:

Penso em voltar para o Recife, obedecendo a pressentimentos de desgraça, receios que me invadem em todas as reuniões da família. Davi e Ismael consultam-me com os olhos; temem que eu desista da viagem. Não dependem de mim para continuar,

mancanza di una rappresentazione prospettica, esse o non offrono quasi nulla da 'vedere', rimanendo nell'elemento puramente linguistico, oppure mostrano qualcosa solo da un punto di vista ideale ed inanimato. La natura ideale della bucolica (locus amoenus), pur avvicinandosi già al paesaggio letterario, apppartiene piuttosto alla categoria della descrizione [...]. Solo dove i testi letterari rimandano alla soggettività, solo dove la soggettività viene ancorata saldamente nel testo, sorgono immagini innovative ed espressive della natura, cioè paesaggi letterari./ Dunque possiamo parlare di paesaggi letterari quando, direttamente o indirettamente, viene connotata l'esperienza vissuta della natura da parte di un osservatore (JAKOB, 2009, p. 40). 
mas sou eu que intervenho nas disputas entre eles, desde quando tocávamos rebanhos de carneiros e feri o calcanhar, numa tarde como esta. / Tudo se assemelha ao passado, até os caminhos repetidos e o silêncio dos mortos, fantasmas que andaram como ando, ansioso e deprimido./Há algum tempo dirijo o carro sozinho. Os primos subiram na carroceria da camioneta, expondo-se ao sol e à poeira do final de tarde, num mês de dezembro com prenúncios de chuva. Tamanha beleza é pura armadilha. Preciso de lentes para abstrair o azul do céu, as nuvens de cinema épico. / O calor me enfada. Ele vem das pedras que afloram por todos os lados, como planta rasteira. Nada lembra mais o silêncio do que a pedra, matéria-prima do sertão que percorremos em alta velocidade. (BRITO, 2009, p. 7).

Nesse excerto, percebemos a rememoração presentificada, definida pela justaposição de uma tarde no passado e a do presente da narração e pela sobreposição dos caminhos dos antepassados aos próprios, fato que também exemplifica a focalização interna da narrativa, pois deixa claro o ponto de vista a partir do qual os fatos serão narrados ao afirmar um "aqui" e um "agora" que correspondem à posição, ou à perspectiva, de Adonias e que revelam a sua subjetividade, pois, segundo Jakob:

Se as paisagens literárias são definidas como textos descritivos ou representativos em relação espacial com a natureza, então, a rigor, o ponto de vista da espacialidade já remete a um sujeito. Para representar a natureza espacialmente - não somente de modo sumário, superficialmente ou em forma de paisagem contentora - é necessário que o texto em questão indique uma perspectiva, a partir da qual (e somente a partir desta) pode emergir ou desvelar uma paisagem. A realização da representação perspectivística no texto ocorre sobretudo mediante sinais orientados de um ponto de vista indicativo: 'eu' - 'agora' - 'aqui' (JAKOB, 2005, p. 39, tradução nossa). ${ }^{4}$

Nesses parágrafos iniciais do romance, percebemos claramente que a junção dessas três categorias - "eu”, "aqui" e "agora" - é responsável por uma definição específica do espaço circundante. Em especial, percebemos como a subjetividade de Adonias, contextualizada por um dado espaço e um dado momento, percebe e adjetiva o sertão, fato evidente quando o narrador-protagonista associa a beleza sedutora do espaço à uma armadilha perigosa. Assim, essa associação, que define a chave de leitura pela qual Adonias "lê" o sertão, não está descolada do sujeito em sua interação com um espaço e um tempo específicos, dado que essa percepção está condicionada a esses três elementos.

Nesse sentido, a expressão "numa tarde como essa", além de informar o local onde se passam as ações, sejam estas as da memória, sejam as do presente da narração, exemplifica o cronotopo do romance, isto é, as relações indissociáveis mantidas entre espaço e tempo, conforme teoriza Bakhtin, para quem o cronotopo é uma categoria "conteudístico-formal", no qual:

[...] ocorre a fusão dos indícios espaciais e temporais num todo compreensivo e concreto. Aqui o tempo condensa-se, comprime-se, torna-se artisticamente visível; o próprio espaço intensifica-se, penetra no movimento do tempo, do enredo e da história. Os índices do tempo transparecem no espaço, e o espaço reveste-se de

\footnotetext{
${ }^{4}$ Se si definisicono i paesaggi letterari come testi descrittivi o rappresentativi in relazione spaziale com a natura, allora a rigore, già il punto di vista della spazialità rinvia ad un soggetto. Per rappresentare la natura spazialmente - non solo in modo sommario, in forma di paesaggio contenitore oppure superficialmente, in forma di elenco linguistico - occorre che il testo in questione indichi una prospettiva, dalla quale ( e soltanto da essa) pùo emergere o dischiudersi un paesaggio.La realizzazione della rappresentazione prospettica nel testo avviene sopratutto mediante segnali orientati da un punto di vista indicatore: 'io' - 'ora' - 'qui'. (JAKOB, 2005, p. 39).
} 
sentido e é medido com o tempo. Esse cruzamento de séries e a fusão de sinais caracterizam o cronotopo artístico (BAKHTIN, 1988, p. 211).

Em Galileia, o cronotopo também é percebido nas Imagens-Paisagens, em especial na inaugural, acima transcrita, uma vez que ela define a relação significativa que o sujeito mantém com o espaço no qual transcorreu parte de sua história individual, revelada e figurativizada pelo sertão. Isso porque, sendo o ambiente sertanejo o espaço onde o passado de Adonias e de sua família transcorreu, ele manifesta e carrega em si índices dessa passagem temporal, impalpável per se, mas tornada sensível e visível espacialmente. Desta feita, "o cronotopo, como materialização privilegiada do tempo no espaço, é o centro da concretização figurativa, da encarnação do romance inteiro" (BAKHTIN, 1988, p. 356). A Paisagem literária seria, nesse sentido, lugar por excelência para a manifestação do cronotopo, dado seu alto grau de figuratividade. Sobre essa questão, Jakob (2009) afirma que a associação entre Paisagem e o aspecto temporal é frequentemente esquecida, ainda que o tempo esteja obrigatoriamente inscrito na Paisagem, caracterizando-a:

Comumente, associamos com facilidade a paisagem e o espaço, esquecendo outra categoria fundamental: o tempo. Segundo definição do geógrafo Yi Fu Tuan, a paisagem, pelo contrário, é efetivamente a irrupção do tempo no espaço: Todo quadro que representa uma paisagem em perspectiva e toda fotografia nos ensinam a ver o tempo atravessar o espaço (JAKOB, 2009, p. 60, tradução nossa). ${ }^{5}$

A figuratividade da Paisagem é construída por meio da representação de um espaço especificado seja pela sua apreensão em um momento singular, seja pela passagem do tempo, que o "historiciza". Se de um lado o espaço é marcado pelo tempo e, assim, "historicizado" diegeticamente, por outro a própria abordagem literária-estética de um espaço revela o contexto temporal e espacial de produção da obra, fato depreendido a partir das análises de Bakhtin, quando este relaciona os cronotopos de gêneros às conjunturas sócio-culturais das sociedades que os produziram. Por essa razão, a Paisagem, segundo a definição de Jakob (2009, p. 10), também é cronotópica, haja visto seu caráter de texto e sua dupla orientação: de um lado, o tempo se inscreve no espaço, deixando suas marcas, de outro, os modos pelos quais o espaço é observado, e transformado em paisagem, conota uma ideologia, também tornada visível na e pela Paisagem.

No caso, o sertão cronotópico de Galileia indica uma abordagem contextual contemporânea do espaço sertanejo por meio da percepção sensorial de Adonias, cuja experiência subjetiva faz confluir tempos distintos no espaço, já marcado pela irrealidade (ou super-realidades) das Imagens poéticas, frequentemente determinadas pela apreensão simultânea de tempos, caso da citação acima.

O espaço sertanejo é, para Adonias, o equivalente da madeleine proustiana, de tal modo que as histórias e sensações do passado se impõem ao presente da narração, em uma copresença típica da "memória-acontecimento", termo criado por Mariana Luz Pessoa de Barros (2011) para explicar a presentificação vívida do passado, em que este não é apenas rememorado, mas experimentado novamente, em fusão com o tempo atual:

\footnotetext{
5 "Di solito, accomuniamo con facilità il paesaggio e spazio, dimenticando l'atra categoria fondamentale: il tempo. Secondo la definizione del geografo Yi Fu Tuan, il paesaggio è invece proprio l'írruzione del tempo nello spazio: "Ogni quadro che rappresenta un paesaggio in prospettiva e ogni fotografia ci insegnano a vedere il tempo attraversare lo spazio" (JAKOB, 2009, p. 60).
} 
Não é apenas o passado que vem à tona, mas a presença de um sujeito no passado. As sensações e emoções são (re)vividas na linguagem pelo enunciador e pelo enunciatário. É este o domínio da experiência sensível (BARROS, 2011, p. 269).

Retomando a definição de acontecimento de Greimas, em Da Imperfeição (2002), em que a experiência sensível predomina e se sobrepõe à racionalidade convencional, e associandoa ao eixo de combinação e seleção de Jakobson, Barros (2011) classifica dois tipos de memória ${ }^{6}$ : uma em que esta ação é racionalmente motivada sendo, por isso, associada à contiguidade e ao eixo sintagmático, e outra em que a experiência sensível determina associações paradigmáticas e, por isso, se desenvolvem analogamente à metáfora.

Por simular a rememoração em ato, as Imagens definidas pela memóriaacontecimento são extremamente sensoriais e estésicas, fato que influencia a apreensão dos valores, significados e conteúdos da obra pelo enunciatário. No caso das Imagens relativas ao espaço, percebemos, além da memória em ato e associadas a esta, simultaneamente uma "subjetividade em ato" (JAKOB, 2005, 2009) e uma "consciência paisagística em ato" (JAKOB, 2009), isto é, a experiência de um personagem que tenta se apropriar da natureza, uma experiência que é simulada esteticamente no caso do romance em questão.

A constatação da simultaneidade dos tempos passado e presente por Adonias é o melhor exemplo da relação cronotópica entre Imagem-Paisagem e memória, evidenciando não apenas o cronotopo geral do romance, mas o motivo da estrada, que figurativiza o primeiro, pois é

[...] o ponto do enlace e o lugar onde se realizam os acontecimentos. Parece que o tempo se derrama no espaço e flui por ele (formando os caminhos); daí a tão rica metaforização do caminho-estrada: "o caminho da vida", "ingressar numa nova estrada", "o caminho histórico" e etc.; a metaforização do caminho é variada e muito planejada, mas o sustentáculo principal é o transcurso do tempo (BAKHTIN, 1988, p. 349-350, grifo nosso).

Quando Adonias atribui identidade entre os caminhos dos antepassados e os que ele percorre no presente, concretizam-se os conceitos desenvolvidos por Bakhtin acerca da estrada, motivo cronotópico que serve de figurativização da passagem temporal. Portanto, nada mais natural que Adonias perceba a estrada como confluência inevitável do passado no presente, confirmando que, no caso de Galileia, a viagem é simultaneamente literal e metafórica, dada a re-vivência do passado familiar e particular, de modo que a estrada que leva à Galileia é, de fato, um "caminho da vida", marcado pelas passagens históricas das quais foi palco.

Percebemos, novamente, a "materialização" das lembranças de Adonias no espaço no trecho a seguir, no qual Adonias recorda-se de um fato que marcou a sua vida: a violência sexual, nunca devidamente explicada, cometida contra o seu primo Davi quando ambos eram crianças: "Estamos sozinhos no descampado dos terreiros, o mesmo cenário onde assisti à cena que tanto me impressionou. Falta apenas o refletor do sol para nos iluminar. No escuro, avisto a silhueta franzina do primo" (BRITO, 2009, p.210).

Nesse trecho, percebemos novamente a mediação de Adonias na abordagem sensível do espaço e a relação entre passado e presente, deixando clara a interligação entre o narradorprotagonista, seu imaginário, o espaço e a narração, pois a presença do sol, na memória de Adonias, interpõe-se à noite - e à falta de sol - do presente narrativo, presentificando o

\footnotetext{
${ }^{6}$ Lembrando que Walter Benjamin teoriza acerca de uma memória voluntária e de uma memória involuntária, ligadas, respectivamente, à vivência e à experiência (BENJAMIN, 1989).
} 
passado e reafirmando a profunda conexão mantida entre a descrição do cenário e a psicologia do personagem. Isso porque o narrador-protagonista, impressionado pela cena vista no passado, a revê mentalmente, como se ela se reencenasse diante dos seus olhos, em um evento típico da memória-acontecimento, na qual o passado volta a ser vivido com intensidade. Dessa forma, o campo de presença do narrador-protagonista parecer ser subitamente invadido pelas personagens e pelos elementos participantes da cena lembrada, como é o caso do sol, o qual, devido ao seu vigor excessivo, marcou qualitativamente, porque sensivelmente, a memória de Adonias.

Desse modo, mesmo na ausência física do sol, a sua Imagem sobressai-se no imaginário do protagonista, devido ao impacto de sua presença, sobretudo em termos psicológicos. No entanto, ao contrário do que acontece em outros trechos do livro, nos quais a onipresença do sol se afirmava em relação aos seus vestígios deixados em elementos do cenário, no presente exemplo esse vestígio é interno à Adonias. Além disso, esse trecho é exemplar no que diz respeito à construção de imagens "haikais", com alta densidade semântica, apesar - ou justamente por conta - de sua sinteticidade.

Como pudemos ver nas citações acima, a percepção do espaço por Adonias é perspassada por uma valorização negativa do espaço, associado a lembranças e histórias da família que o angustiam. Na cena seguinte, no entanto, as referências ao espaço ultrapassam a mera constatação dos aspectos negativos e áridos do cenário. Isso porque as situações vivenciadas no momento são positivas, já que ele está em companhia do primo favorito, único com quem o narrador-protagonista mantém relações de afetividade sincera, senão de erotismo, e em conjunção com o meio que o cerca, um espaço primeiramente percebido como local de memórias infantis, motivando uma abordagem positiva - e voluptuosa - da natureza:

\footnotetext{
Descanso. Quando fico ansioso, não enxergo nada, os sentidos se fecham para o mundo. Agora sei onde estou e aonde posso ir. Os olhos se reabrem, as narinas aspiram cheiros de flores, ouço aqui e acolá um canto de passarinho. O lugar é bonito, um santuário de ninfas. Depois de uma longa ausência, meu corpo responde, acorda quase feliz. Grito mais alto, rodopio, tiro a camisa, descalço os sapatos, pareço estar num transe xamânico (BRITO, 2009, p. 130).
}

Nesse trecho, há referência a elementos que denotam abundância de vida, caso das flores, que são metáfora da fertilidade, e dos passarinhos, cuja presença sonora quebra o silêncio, anteriormente associado à aridez e à morte. Dessa forma, as figuras das flores e dos passarinhos oferecem uma inversão da dominante Imagem-Paisagem, porque nesse momento a ansiedade de Adonias dá trégua, fazendo com que ele perceba o espaço não só como belo, mas idílico e mítico. Assim, nesse trecho, percebemos que existe um projeto de reintegração do sujeito com a natureza, evitando a abordagem científica/objetiva que caracteriza o sujeito moderno, situação que remonta às concepções de Jakob acima citadas sobre a separação irremediável entre o homem moderno e a natureza, bem como a tentativa, por parte do sujeito, de superar essa "crise fundadora".

Esse fato é comprovável pela menção a um santuário de ninfas, associando um lugar sacro a seres ligados à natureza e à abundância de vida. Dessa forma, a leitura do espaço passa, nessa cena, por uma inversão, pois de um lado temos um texto literal, que descreve uma paisagem fecunda e, de outro, um texto figurado que revela que a percepção do espaço deriva do estado de espírito de Adonias, imerso em boas recordações de sua infância e, consequentemente, em conexão com a natureza circundante. Fato que remete à concepção de Paisagem segundo definição de Jakob: 
A paisagem é o resultado artificial, não natural, de uma cultura que re-define perpetuamente a sua relação com a natureza. Isso remete a um paradoxo: a experiência da paisagem é, em geral e em primeiro lugar, uma experiência de si próprio. Portanto, tanto aquilo que o sujeito percebe quanto o ato de perceber como tal são importantes. O sujeito faz completamente parte da paisagem que compõe. Daí a não-identidade profunda da paisagem, da história da paisagem, ou melhor, da história da consciência da paisagem. A paisagem não existe senão como consciência ou, antes, é essa consciência (JAKOB, 2009, p. 29, tradução nossa) ${ }^{7}$.

Isto é, independentemente da positivação de valores atribuídos ao espaço, a ImagemPaisagem do sertão é, obrigatoriamente, resultado da experiência de um sujeito e da sua perspectiva, sem as quais a Paisagem não existe como experiência sensorial e categoria estética, sendo apenas cenário. Por isso, a nova experiência de si próprio gera, em Adonias, uma nova consciência do espaço, menos marcada pela irremediável outridade desse, mas sentida como parte intrínseca da própria existência e subjetividade.

Adonias experimenta, então, um novo êxtase sensorial, que amplia a sua percepção, desautomatizando e ultrapassando as representações usuais que medeiam a sua interação com o espaço, fato que remete à Paisagem, mas sob um novo enfoque, em que a conjunção máxima com a realidade possui conotações positivas. Neste caso, a experiência paisagística é transcendente, haja visto que Adonias compara a euforia dos seus sentidos a um "transe xamânico", vivência inovadora para ele, acostumado a "fechar" os sentidos não só por conta da ansiedade que o domina, mas em nome da racionalidade e da lógica. Essas características, como vimos acima, são típicas do homem moderno em relação à natureza, de quem está distanciado. No entanto, mesmo com uma nova percepção do espaço, essa continua sendo marcada por uma profunda subjetividade em ato, de tal maneira que Adonias ainda percebe a natureza como uma vivência particular, a qual reflete o seu próprio estado de espírito.

Essa última citação comprova a nossa hipótese inicial de que, em Galileia, existe uma Paisagem, conforme concepção de Jakob, dada a perspectiva subjetiva de Adonias na apresentação do espaço natural, de forma que, durante seus estados de instabilidade emocional, a natureza circundante é enquadrada apenas em seus aspectos negativos, direcionando a sua percepção sensorial do espaço ao seu redor. Já em raros momentos, como a passagem acima, o cenário não é visto como antagonista, como "armadilha sedutora", conforme a primeira citação do romance, mas como refúgio idílico e, até mesmo, sensual. Além dos conceitos de Jakob, a criação de uma imagem espacial mediada pela psicologia do narrador protagonista também é evidenciada, como vimos, pelo conceito de cronotopo, de Bakhtin, e pela manifestação das memórias-acontecimentos, segundo terminologia de Maria Luz Pessoa de Barros, dado que o espaço do narrador-protagonista subitamente é "invadido" por elementos do seu passado.

\section{Referências}

BENJAMIN, W. Obras escolhidas III. Charles Baudelaire, um lírico no auge do capitalismo.

\footnotetext{
7 "Il paesaggio è il risultado artificiale, non naturale, di una culltura che ri-definisce perpetuamente la sua relazione con la natura. Questo rinvia a un paradosso: l'esperienza del paesaggio è, in generale e in primo luogo, un'esperienza di sé. È importante quindi sia ciò che il soggetto percepisce sia l'atto di percepire in quanto tale. Il soggetto fa interamente parte del paesaggio che compone. Da qui la non-identità profonda del paesaggio, la storia del paesaggio o meglio la storia della coscienza del paesaggio. Il paesaggio non esiste che in quanto coscienza, o anzi, è questa coscienza" (JAKOB, 2009, p. 29).
} 
Tradução de José Carlos Martins Barbosa e Hemerson Alves Baptista. São Paulo: Editora Brasiliense, 1989.

BAKHTIN, M. Questões de Literatura e Estética. Tradução de Aurora Fornoni Bernadini. São Paulo: Editora da UNESP e Hucitec, 1988.

BARROS, M.L.P. O discurso da memória: Entre o sensível e o inteligível. 2011, 307f. Tese (Doutorado em Semiótica e Linguística) - Universidade de São Paulo, São Paulo.

BRITO, R.C. Galileia. Rio de Janeiro: Objetiva, 2009.

GREIMAS, A. J. Da Imperfeição. Trad. Ana Claúdia de Oliveira. São Paulo: Hacker, 2002.

JAKOB, M. Il paesaggio. Bologna: Il Mulino, 2009.

JAKOB, M. Paesaggio e letteratura. Firenze: Leo S. Olschki, 2005.

Recebido em: 27 de julho de 2020 Aceito em: 01 de dezembro de 2020

Publicado em dezembro de 2020 